\title{
Structural Analysis of Compressor Blades for Turbocharger by Using the Different Materials
}

\author{
Ni Ni Hlaing ${ }^{1}$ Htay Htay Win ${ }^{2}$, Myint Thein ${ }^{3} \&$ Aung Ko Latt ${ }^{4}$ \\ Ph.D Candidate ${ }^{1}$ Professor $^{2-3}$ and Associate Professor ${ }^{4}$ \\ Department of Mechanical Engineering \\ Mandalay Technological University \\ Mandalay, Mandalay Division
}

Myanmar

\begin{abstract}
A structural analysis has been carried out to investigate the Von-Mises stresses, effective strains and total deformation of the compressor blades of the turbocharger in locomotive diesel engines. An investigation in the usage of new materials is required. In this research, compressor blades are designed with three different materials. The modeling of the compressor is drawn by using SolidWorks (2016) software and analysis is done in ANSYS (17.0). The design speed of the compressor is considered 68,000 rpm. An attempt is also made to suggest the suitable material for the compressor blades of a turbocharger by comparing the results obtained for three different materials (Aluminum Alloy (7050-T7651), AISI 4340 Steel and Inconel Alloy (718)) for the compressor. The Aluminum Alloy (7050-T7651) for the compressor blades of a turbocharger is recommended on the suitable results than the other two materials
\end{abstract}

Key Words: Compressor Blades, Effective Strain, Total Deformation, Turbocharger, Stress Analysis, Material.

\section{INTRODUCTION}

Turbochargers are a class of turbo machinery these are to increase the power of internal combustion engines. This is working by increasing the pressure of intake air, allowing more fuel to be combusted. Rudolf Diesel and Gottlieb Daimler experimented with pre-compressing air to increase the power output and fuel efficiency in the late 19th century. The first exhaust gas turbocharger was done completely in 1925 by the Swiss engineer Alfred Buchi who introduced a prototype to increase the power of a diesel engine by a reported $40 \%$. At that time, the idea of turbo charging was not widely accepted [1].

A turbocharger consists of a compressor with impeller and turbine with impeller operating on a single common shaft. These are often investigated for use on automobile internal combustion engines. The hot exhaust gases exiting the cylinders pass through the turbine side of the turbocharger, tunning the turbine blades, and thus the shaft. The shaft then generated power to drive the compressor. The exhaust gases then continue out to the exhaust manifold and continue as usual. As the compressor turns, it raises the pressure of the incoming air from the air intake. The high pressure air is often allowed through a charged air cooler (also known as an intercooler) to further raise the density of the air [5]. Figure 1 shows the operation of turbocharger.

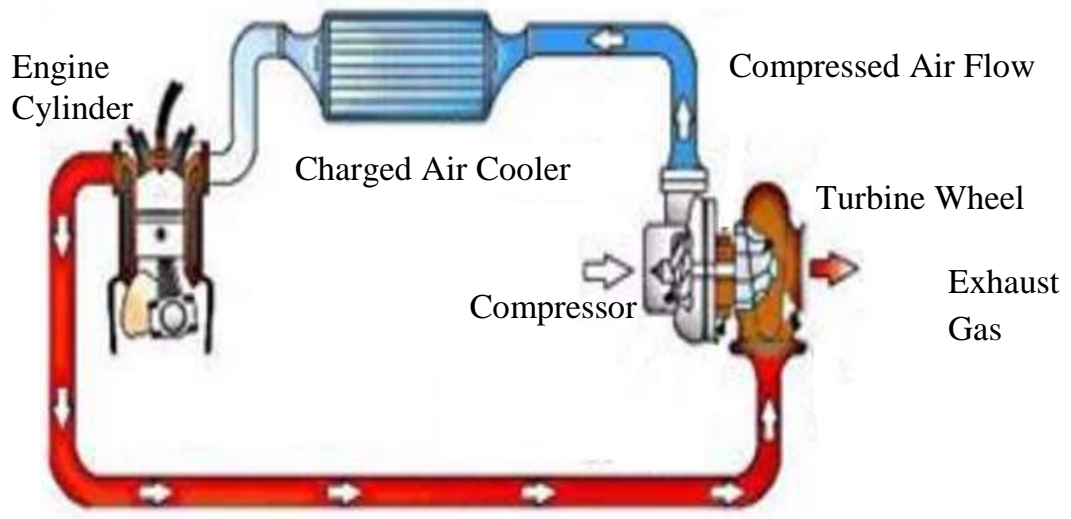

Figure 1. Operation of Turbocharger [5] 


\section{DESIGN OF COMPRESSOR IMPELLER FOR TURBOCHARGER}

Consider a design of centrifugal compressor impeller, the shape of an impeller is the most important for optimum efficiency. Computational procedure is based on the specified parameters.

\subsection{Design Procedure for Centrifugal Compressor}

In this research, the design parameter of impeller is pitched up at 'Diesel Locomotive Workshop (YWAHTAUNG)'. The centrifugal compressor of the station has the following parameter;

$\begin{array}{ll}\text { Power } & =810 \mathrm{~kW} \\ \text { Outlet Temperature, } \mathrm{T}_{2} & =408 \mathrm{~K} \\ \text { Capacity, } \mathrm{Q} & =0.19 \mathrm{~m}^{3} / \mathrm{sec} \\ \text { Outlet Pressure, } \mathrm{P}_{2} & =500 \mathrm{kPa} \\ \text { Air mass flow rate, } \mathrm{m}^{\circ} & =1.6 \mathrm{~kg} / \mathrm{sec} \\ \text { Slip factor, } \sigma & =0.85\end{array}$

Ambient pressure and ambient temperature is 1.2 bars and $30^{\circ} \mathrm{C}$. Figure 2 shows entry and exit velocity triangles for impeller.

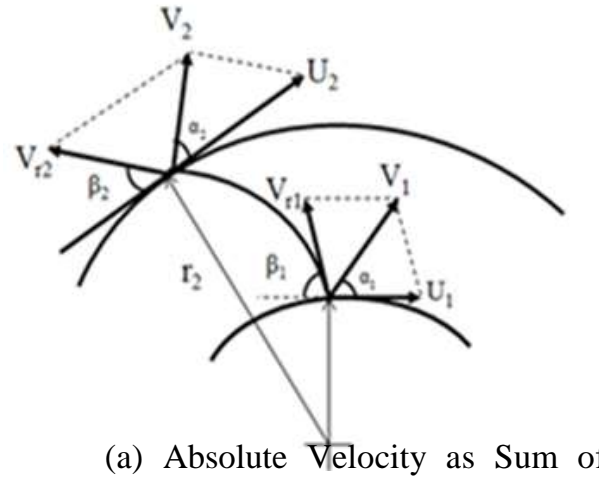
Velocity Relative to Blade

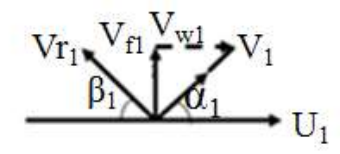

(b). Inlet Velocity Component

Figure 2. Entry and Exit Velocity Triangles for Impeller

Design calculation divided into five main parts for turbocharged compressor. There were

(i) Calculation of Impeller Inlet Dimensions

(ii) Calculation of Impeller Outlet Dimensions

(iii) Efficiency of Compressor

(iv) Calculation of Stress on Compressor Impeller

(v) Calculation of Strain on Compressor Impeller

\subsubsection{Calculation of Impeller Inlet Dimensions}

Impeller inlet and outlet pressure ratio,

$$
r_{\mathrm{P}}=\frac{\mathrm{P}_{2}}{\mathrm{P}_{1}}
$$

Shaft Diameter, $\mathrm{D}_{\mathrm{s}}$ (Aluminum Alloy (7050-T7651))

Standard shaft diameter is up to $25 \mathrm{~mm}$ [13].

$$
D_{S}=\sqrt[3]{\frac{16 T}{\pi \times S_{s}}}
$$

Impeller Inlet Velocity and Inlet Blade Angle

The air enters the impeller eye to tip in the axial direction. The prewirl angle is zero so that $\mathrm{V}_{1}=\mathrm{V}_{\mathrm{f} 1}$.

$$
\mathrm{D}_{1}=1.025 \times \mathrm{D}_{0}
$$

Inlet Absolute Velocity, $\mathrm{U}_{1}$

$$
\mathrm{U}_{1}=\frac{\pi \mathrm{D}_{1} \mathrm{~N}}{60}
$$


Inlet Blade Angle, $\beta_{1}$

$$
\beta_{1}=\tan \frac{\mathrm{V}_{1}}{\mathrm{U}_{1}}
$$

\subsubsection{Calculation of Impeller Outlet Dimensions}

Impeller Outlet diameter, $\mathrm{D}_{2}$

Assume $\mathrm{K}^{\prime}=0.55$

$$
\mathrm{D}_{2}=\frac{60 \sqrt{\mathrm{H}_{\mathrm{pg}}}}{\pi \mathrm{N} \sqrt{\mathrm{K}^{\prime}}}
$$

$\mathrm{K}^{\prime}$ is the pressure coefficient which has a value between 0.5 and 0.65 depending on the type of impeller.

The Outlet Peripheral Velocity, $\mathrm{U}_{2}$

\subsubsection{Efficiency of Compressor}

$$
\mathrm{U}_{2}=\frac{\pi \mathrm{D}_{2} \mathrm{~N}}{60}
$$

Compressor Efficiency, $\eta_{\mathrm{c}}$ is

$$
\eta_{\mathrm{c}}=\frac{\text { Output }}{\text { Input }}=\frac{\rho g Q \mathrm{H}}{\mathrm{C}_{\mathrm{p}}\left(\mathrm{T}_{02}-\mathrm{T}_{01}\right)}
$$

\subsubsection{Calculation Stress on Compressor Impeller}

There are two forces on the compressor impeller. The centrifugal force, $\mathrm{F}_{\mathrm{c}}$

$$
\mathrm{F}_{\mathrm{c}}=\operatorname{mr} \omega^{2}
$$

The gas bending force, $\mathrm{F}_{\mathrm{b}}$

$$
\mathrm{F}_{\mathrm{b}}=\mathrm{m}^{\circ} \mathrm{V}_{\omega 2}
$$

The most important components of static stresses are centrifugal stress and gas bending stress. The centrifugal stress can be determined as follows. The centrifugal stress, $\sigma_{c}$

$$
\sigma_{c}=\frac{\rho \omega^{2}}{2}\left(r_{t}^{2}-r_{r}^{2}\right)
$$

The gas bending stress can be calculated as follows;

$$
\sigma_{\mathrm{gb}}=\frac{\mathrm{m}^{\circ}\left(\mathrm{C}_{\mathrm{w}-\mathrm{in}}+\mathrm{C}_{\mathrm{w} \text {-out }}\right) \times \mathrm{h}_{\mathrm{R}}}{2 \times \mathrm{n}_{\mathrm{R}} \times \mathrm{Z} \times \mathrm{c}_{\mathrm{R}}^{3}}
$$

In the principle stress theory, failure will occur when the principle stress in the complex system reaches the value of the maximum stress at the elastic limit in simple tension. The principal stresses are determined by the following equation.

$$
\sigma_{1}, \sigma_{2}=\frac{\sigma_{x}+\sigma_{y}}{2} \pm \frac{1}{2} \sqrt{\left(\sigma_{x}-\sigma_{y}\right)^{2}+4 \tau_{x y}{ }^{2}}
$$

The von-Mises stress is calculated by the following equation;

$$
\sigma_{\mathrm{V}}=\frac{1}{\sqrt{2}} \sqrt{\left(\sigma_{1}-\sigma_{2}\right)^{2}+\left(\sigma_{2}-\sigma_{3}\right)^{2}+\left(\sigma_{3}-\sigma_{1}\right)^{2}}
$$

\subsubsection{Calculation Strain on Compressor Impeller}

If three principle stresses are applied simultaneously, each causes Poisson strains in the directions and the three dimensional form of Hook's law would show that,

$$
\begin{aligned}
& \varepsilon_{1}=\frac{1}{\mathrm{E}}\left[\sigma_{1}-v\left(\sigma_{2}+\sigma_{3}\right)\right] \\
& \varepsilon_{2}=\frac{1}{\mathrm{E}}\left[\sigma_{2}-v\left(\sigma_{1}+\sigma_{3}\right)\right] \\
& \varepsilon_{3}=\frac{1}{\mathrm{E}}\left[\sigma_{3}-v\left(\sigma_{1}+\sigma_{2}\right)\right]
\end{aligned}
$$


For the von-Mises criterion, the effective strain is given by;

$$
\bar{\varepsilon}=\left[\frac{2}{3}\left(\varepsilon_{1}{ }^{2}+\varepsilon_{2}{ }^{2}+\varepsilon_{3}{ }^{2}\right)\right]^{1 / 2}
$$

Table 1.Results Data of Compressor (Aluminum Alloy)

\begin{tabular}{|c|c|c|c|}
\hline No. & Name & Value & Units \\
\hline 1 & Pressure ratio, $\mathrm{r}_{\mathrm{p}}$ & 4.167 & $\mathrm{~mm}$ \\
\hline 2 & Shaft Diameter, $\mathrm{D}_{\mathrm{s}}$ & 12 & degree \\
\hline 3 & Inlet Blade Angle, $\beta_{1}$ & 33 & degree \\
\hline 4 & Outlet Blade Angle, $\beta_{2}$ & 65 & $\mathrm{~mm}$ \\
\hline 5 & Number of blades, $\mathrm{n}$ & 14 & $\mathrm{~mm}$ \\
\hline 6 & Impeller Inlet Diameter, $\mathrm{D}_{1}$ & 51.1 & $\%$ \\
\hline 7 & Impeller Outlet Diameter, $\mathrm{D}_{2}$ & 169.8 & $\mathrm{~N}$ \\
\hline 8 & Compressor Efficiency, $\eta_{\mathrm{c}}$ & 92.58 & $\mathrm{~N}$ \\
\hline 9 & Centrifugal Force, $\mathrm{F}_{\mathrm{c}}$ & 10491 & $\mathrm{MPa}$ \\
\hline 10 & Gas Bending Force, $\mathrm{F}_{\mathrm{gb}}$ & 790.54 & $\mathrm{MPa}$ \\
\hline 11 & The Centrifugal Stress, $\sigma_{\mathrm{c}}$ & 110.71 & $\mathrm{MPa}$ \\
\hline 12 & The Gas Bending Stress, $\sigma_{\mathrm{gb}}$ & 3.4859 & - \\
\hline 13 & von-Mises Stress, $\sigma_{\mathrm{v}}$ & 59.93 & \\
\hline 14 & Effective Strain, & $7.52 \times 10^{-4}$ & \\
\hline
\end{tabular}

Table 1 describes results data of compressor for Aluminum Alloy (7050-T7651).

\section{STRUCTURAL ANALYSIS OF COMPRESSOR}

The analysis involved in the use of ANSYS (17.0) software. The model is created using SolidWorks (2016) and analyzed using ANSYS (17.0) for compressor impeller with different materials. In this paper, it is investigated the variation of von-Mises stress and effective strain for three materials of compressor impeller. There is in the following steps

(i) Selecting analysis system to be used for modeling after starting ANSYS (17.0).

(ii) Selection the material of rotor blade in engineering data

(iii) Adding geometry to read into the design modeler

(iv) Meshing

(v) Static Structural Analysis

Table 2 Properties of Materials

\begin{tabular}{|c|c|c|c|c|}
\hline Properties & Aluminium Alloy(7050-T7651) & AISI (4340) Steel & Inconel Alloy (718) & Units \\
\hline Elastic Modulus (E) & 72 & 205 & 205 & $\mathrm{GPa}$ \\
\hline Poisson's ratio (v) & 0.33 & 0.32 & 0.284 & $\mathrm{~kg} / \mathrm{m}^{3}$ \\
\hline Density $(\rho)$ & 2830 & 7850 & 8190 & $\mathrm{MPa}$ \\
\hline Yield Strength $\left(\sigma_{\mathrm{y}}\right)$ & 490 & 710 & 1120 & $\mathrm{MPa}$ \\
\hline $\begin{array}{c}\text { Ultimate } \\
\text { Strength }\left(\sigma_{\mathrm{u}}\right)\end{array}$ & 550 & 1110 & 827 & $\mathrm{Ma}$ \\
\hline
\end{tabular}

\subsection{Analysis System}

The static structural simulation was performed on compressor blade by using ANSYS 17.0 software.

\subsection{Material Selection}


Three types of materials are chosen for the material selection. They are aluminum alloy (7050-T7651) with yield strength $490 \mathrm{MPa}$, AISI (4340) steel with yield strength $710 \mathrm{MPa}$ and Inconel alloy with yield strength 827MPa.

\subsection{Geometry}

In this simulation, the SolidWorks (2016) software is used of the design of solid model as an external geometry file to import into the ANSYS 17.0. Two types of geometry are used for compressor blade. One is for the flow analysis using CFX-Pre and other is for static structural analysis. Results data from the CFX-Pre are imported to the structural analysis as input data to get the stress distribution of compressor blade. Figure 3 shows the geometry model of the blade for CFX-Pre which was drawn in SolidWorks software and imported to ANSYS (17.0).

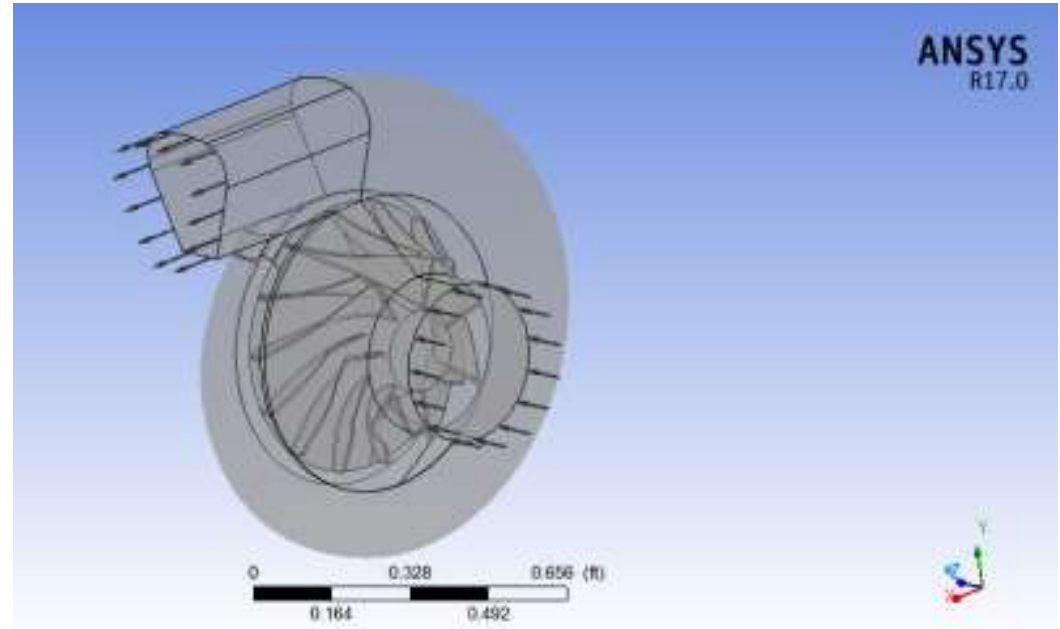

\subsection{Meshing}

Figure 3. Geometry Model of the Compressor for CFX-PRE

Meshing of the compressor has been done using ANSYS 17.0. There are three types of mesh namely Coarse, Medium and Fine. Figure 4 shows the fine meshed model of the compressor blades for CFX-Pre. This mesh model has 66003 nodes and 344759 elements.

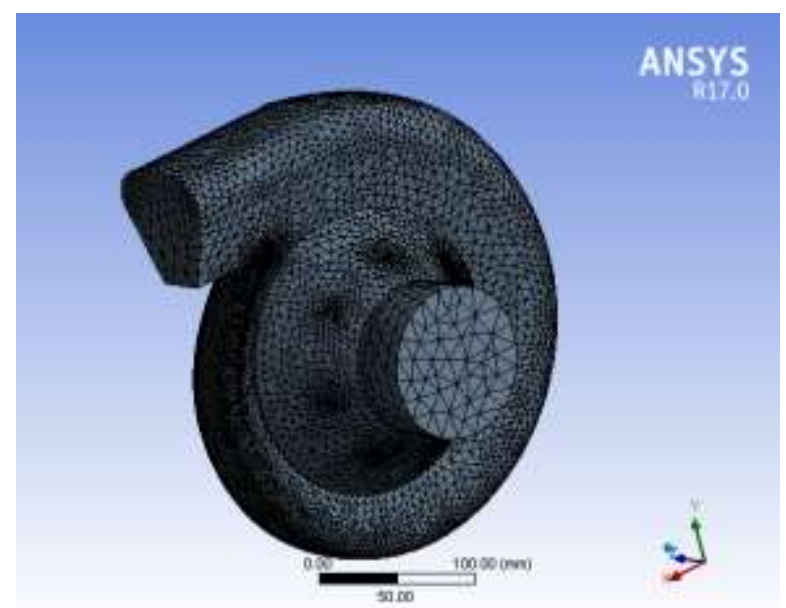

Figure 4. Meshed Model of the Compressor Blades for CFX-Pre

\subsection{Static Structural Analysis}

A static structural analysis determines the von-Mises stresses, strains, and total deformation in structures or components caused by loads that do not induce significant inertia and damping effects. A model of compressor blade was imported to ANSYS 17.0 and setting up the boundary conditions for static structural. There are three important boundaries for structural; imported pressure (result data from the CFX), the centrifugal force and fixed support. Figure 5 shows the project schematic for static structural of compressor blades. 

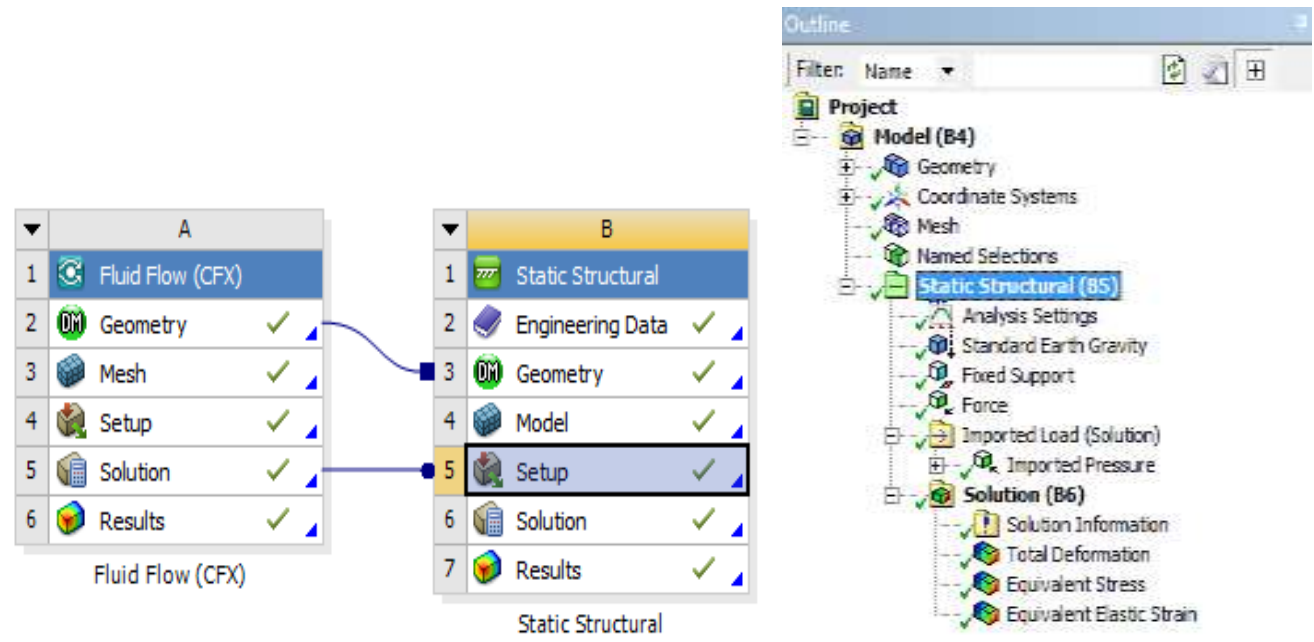

Figure 5. Project Schematic for static structural of compressor blades

There are three boundary conditions for static structural; imported pressure which is the result data of CFX, the centrifugal force and fixed support .The imported pressure is subjected to four walls and fixed support is subjected to top of the compressor. Figure 6 shows the boundary conditions for static structural analysis of compressor blades.

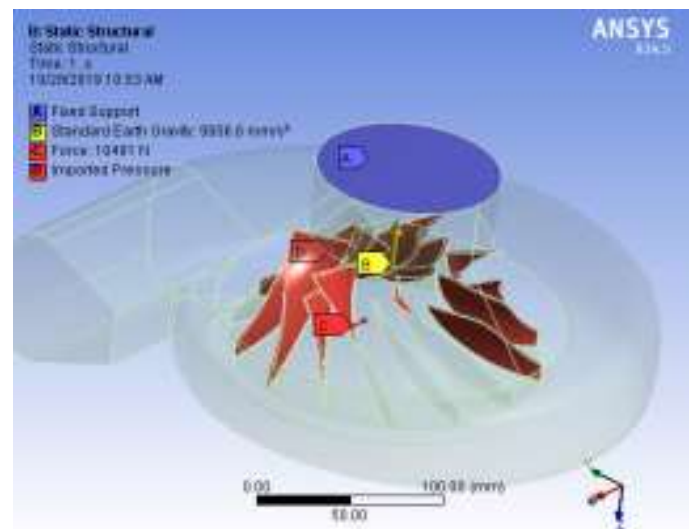

Figure 6. Boundary Conditions for Static Structural Analysis of Compressor Blades

\subsubsection{Numerical Results of von-Mises Stress on Compressor Blades}

Figure 7 shows the equivalent (von-Mises) stress on blade using Aluminum Alloy (7050-T7651). The equivalent (vonMises) stress on blade is $28.66 \mathrm{MPa}$ while the yield strength of the Aluminum Alloy (7050-T7651) is $490 \mathrm{MPa}$. The blade will work safely at this stress.

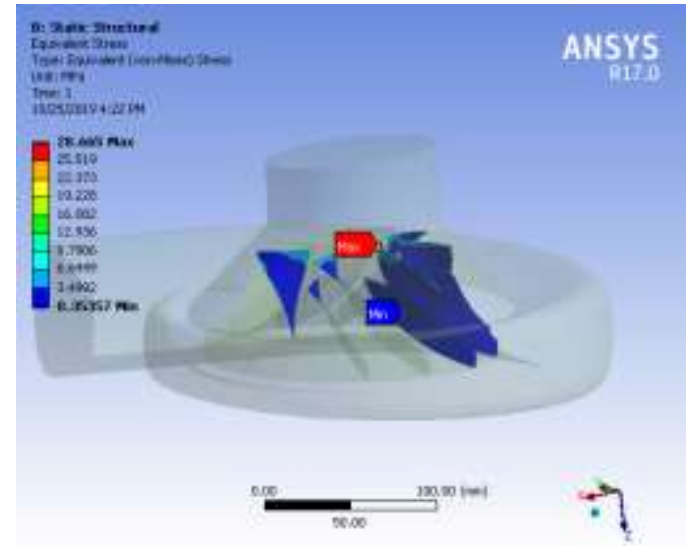

Figure 7. Equivalent (von-Mises) Stress on Compressor Blades using Aluminum Alloy (7050-T7651) 
International Journal of Advances in Scientific Research and Engineering (ijasre), Vol 5 (12), December-2019

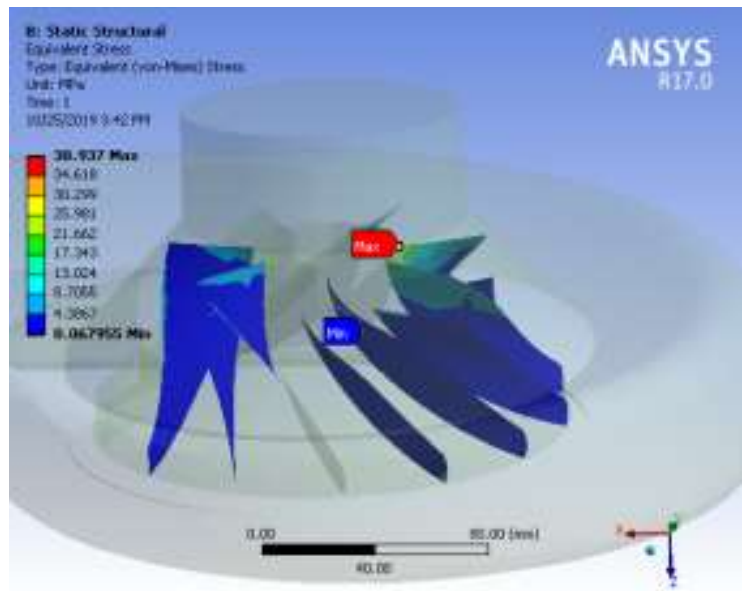

Figure 8. Equivalent (Von-Mises) Stress on Compressor Blades Using AISI (4340) Steel

Figure 8 shows the equivalent (von-Mises) stress on blade using AISI (4340) steel. The equivalent (von-Mises) stress on blade is $38.94 \mathrm{MPa}$ while the yield strength of the AISI (4340) steel is $710 \mathrm{MPa}$. The blade will work safely at this stress.

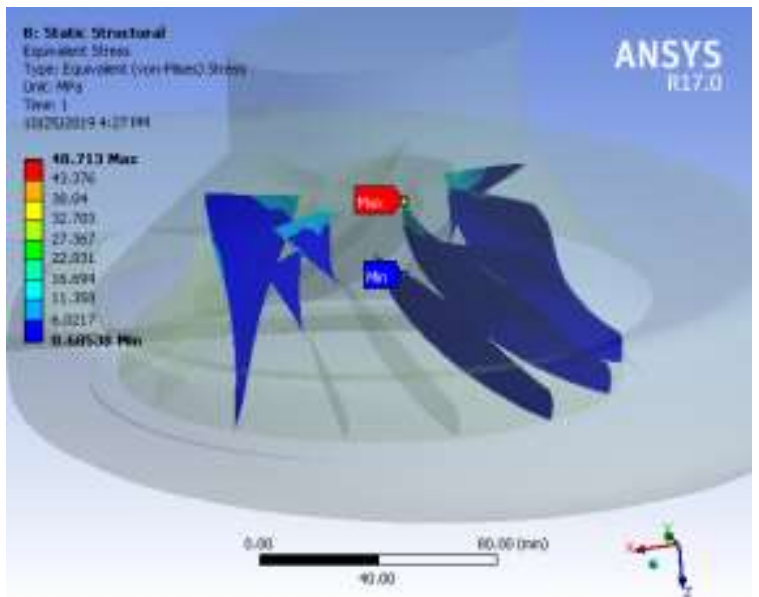

Figure 9. Equivalent (von-Mises) Stress on Compressor Blades Using Inconel Alloy (718)

Figure 9 shows the equivalent (von-Mises) stress on compressor blades using Inconel alloy (718). The equivalent (vonMises) stress on blade is $48.71 \mathrm{MPa}$ while the yield strength of the Inconel alloy (718) is $827 \mathrm{MPa}$. The blade will work safely at this stress.

\subsubsection{Numerical Results of Effective Strain on Compressor Blades}

The numerical results of effective strain on blade are analyzed with static structural on ANSYS 14.5 by changing three different materials namely aluminum alloy (7050-T7651), AISI (4340) steel and Inconel alloy (718).

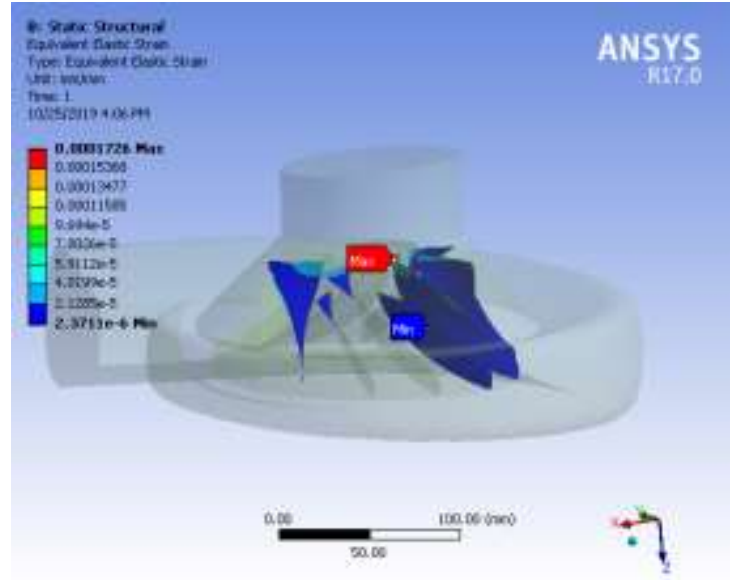

Figure 10. Effective Strain on Compressor Blades using Aluminum Alloy (7050-T7651) 
Figure 10 shows the effective strain on blade with aluminum alloy (7050-T7651). The elastic strain on blade using Aluminum Alloy (7050-T7651) was $1.72 \times 10^{-4}$ at inlet potion of the blades. In the inlet potion of the blades, the effective strain was increased by the forces.

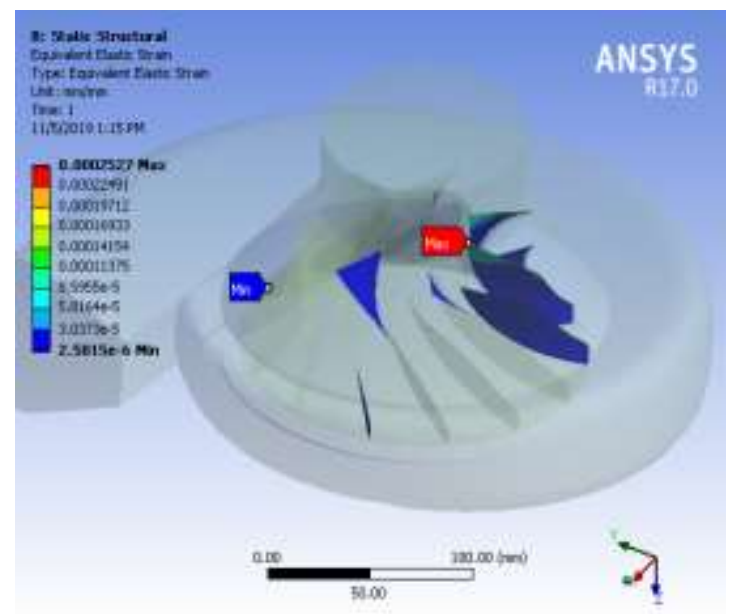

Figure 11. Effective Strain on Compressor Blades using AISI (4340) Steel

Figure 11 shows the effective strain on blade with AISI (4340) Steel. The elastic strain on blade using aluminum alloy (7050-T7651) was $2.53 \times 10^{-4}$ at inlet potion of the blades. In the inlet potion of the blades, the effective strain was increased by the forces.

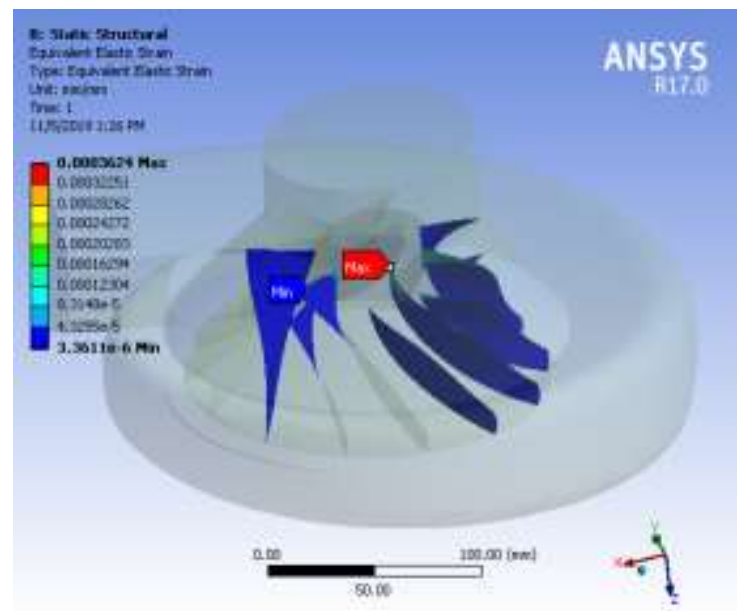

Figure 12. Effective Strain on Compressor Blades using Inconel Alloy (718)

Figure 12 shows the effective strain on blade with Alloy (718). The elastic strain on blade using aluminum alloy (7050T7651) was $3.62 \times 10-4$ at inlet potion of the blades. In the inlet potion of the blades, the effective strain was increased by the forces.

\subsubsection{Numerical Results of Total Deformation on Compressor Blades}

The numerical results of total deformation on blade are analyzed with static structural on ANSYS 14.5 by changing three different materials namely Aluminum Alloy (7050-T7651), AISI (4340) steel and Inconel alloy (718). 


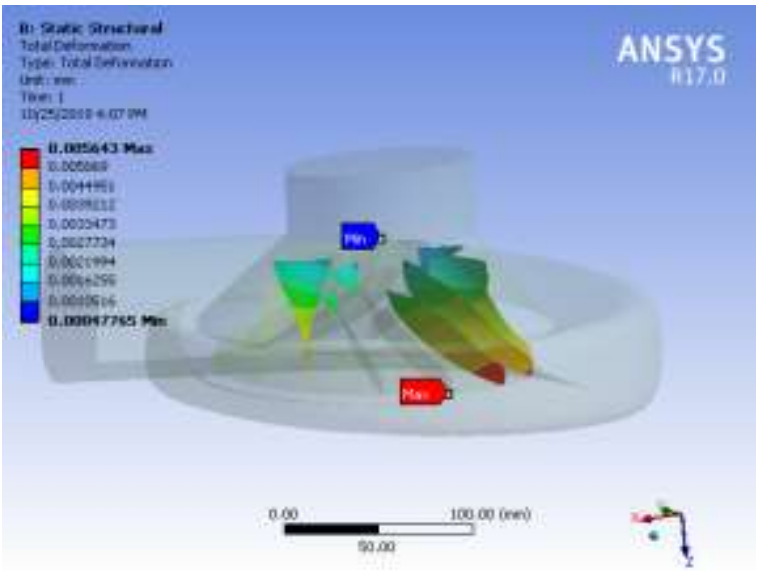

Figure 13. Total Deformation on Compressor Blades using Aluminium Alloy (7050-T7651)

Figure 13 shows the total deformation on blade with Aluminum Alloy (7050-T7651). The total deformation on blade using Aluminum Alloy (7050-T7651) was $0.0056 \mathrm{~mm}$ at outlet potion of the blades. In the outlet potion of the blades, the total deformation was increased by the output air pressure.

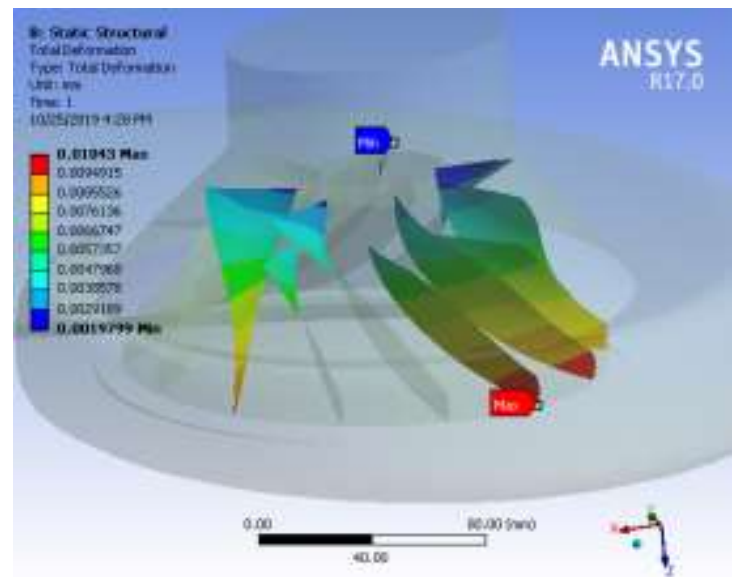

Figure 14. Total Deformation on Compressor Blades using AISI (4340) Steel

Figure 14 shows the total deformation on blade using AISI (4340) steel. The total deformation on blade using AISI (4340) steel was $0.0104 \mathrm{~mm}$ at outlet potion of the blades. In the outlet potion of the blades, the total deformation was increased by the output air pressure.

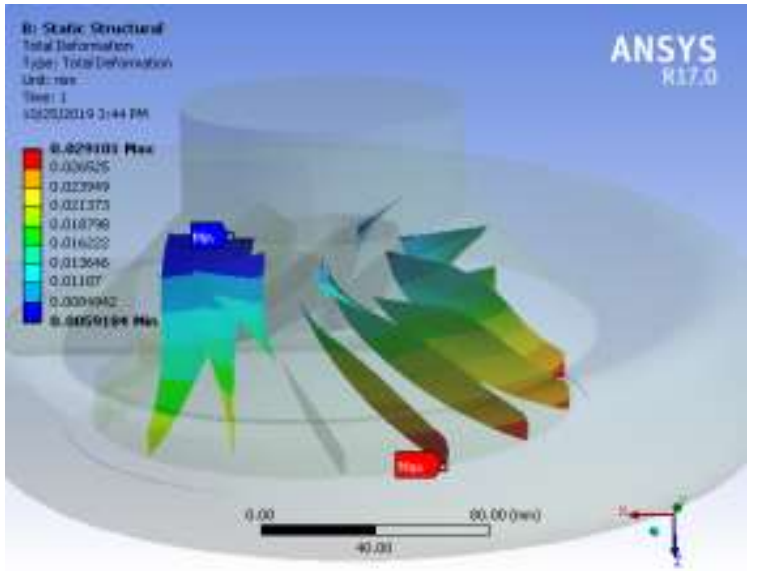

Figure 15. Total Deformation on Blade using Inconel Alloy (718)

Figure 15 shows the total deformation on blade using Inconel alloy (718). The total deformation on blade using Inconel alloy (718) was $0.0291 \mathrm{~mm}$ at outlet potion of the blades. In the outlet potion of the blades, the total deformation was increased by the output air pressure. 
International Journal of Advances in Scientific Research and Engineering (ijasre), Vol 5 (12), December-2019

\section{RESULTS AND DISCUSSION}

Comparative study on static structure analysis has been carried out on compressor blades made of different materials namely Aluminum Alloy (7050-t7651), AISI (4340) steel and Inconel alloy (718) which are suitable for compressor blades. Table 3 shows von-Mises stress, effective strain and total deformation on compressor blades with three types of materials.

Table 3 von-Mises Stress, Effective strain and Total Deformation on Compressor Blades with Three Types of Materials

\begin{tabular}{|l|c|c|c|c|}
\hline \multicolumn{1}{|c|}{ Results } & Aluminium Alloy (7050-T7651) & AISI (4340) Steel & Inconel Alloy (718) & Unit \\
\hline $\begin{array}{l}\text { Equivalent } \\
\text { von-Mises Stress }\end{array}$ & 28.52 & 42.71 & 59.88 & $\mathrm{MPa}$ \\
\hline Effective Strain & $1.72 \times 10^{-4}$ & $2.53 \times 10^{-4}$ & $3.62 \times 10^{-4}$ & - \\
\hline Total Deformation & 0.0056 & 0.0104 & 0.0291 & $\mathrm{~mm}$ \\
\hline
\end{tabular}

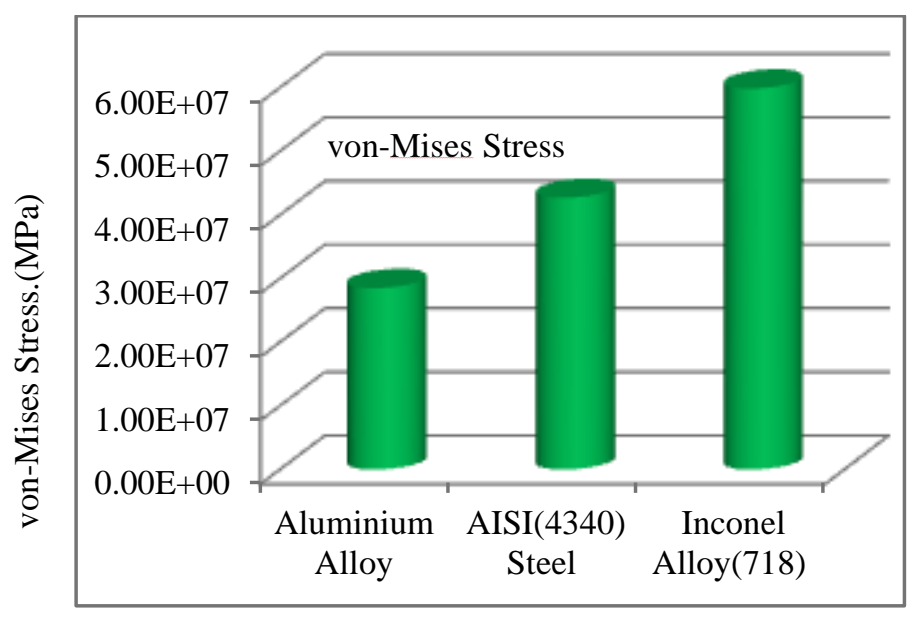

Figure 16. Comparison Results for von-Mises Stress

Figure 16, Figure 17 and 18 show comparison results for von-Mises stress, elastic strain and total deformation. The resulted data for static structural analysis with three types of materials are compared with von-Mises stress, effective strain and total deformation. The maximum von-Mises stress on compressor blades are 28.66 MPa, 38.94 MPa and 48.71 MPa, effective strain are $1.72 \times 10^{-4}, 2.53 \times 10^{-4}$ and $3.62 \times 10^{-4}$ and maximum displacement on compressor blades are $0.0056 \mathrm{~mm}, 0.0104 \mathrm{~mm}$ and $0.0291 \mathrm{~mm}$, respectively. From the structural contours of ANSYS, it can be observed that the total deformation is maximum at outlet end portion of the blade. The von-Mises stress and effective strain on the compressor blades are the minimum value than other two materials. The deformation analysis by using aluminum alloy (7050-T7651) on the compressor blades has minimum values and chooses the aluminum alloy (7050-T7651) for suitable material in this designed compressor blades.

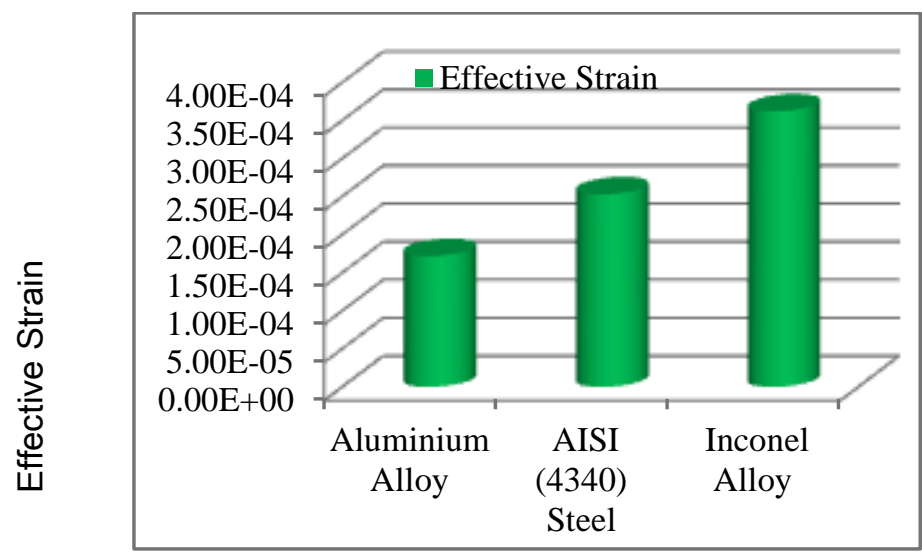

Figure 17. Comparison Results for Effective Strain 


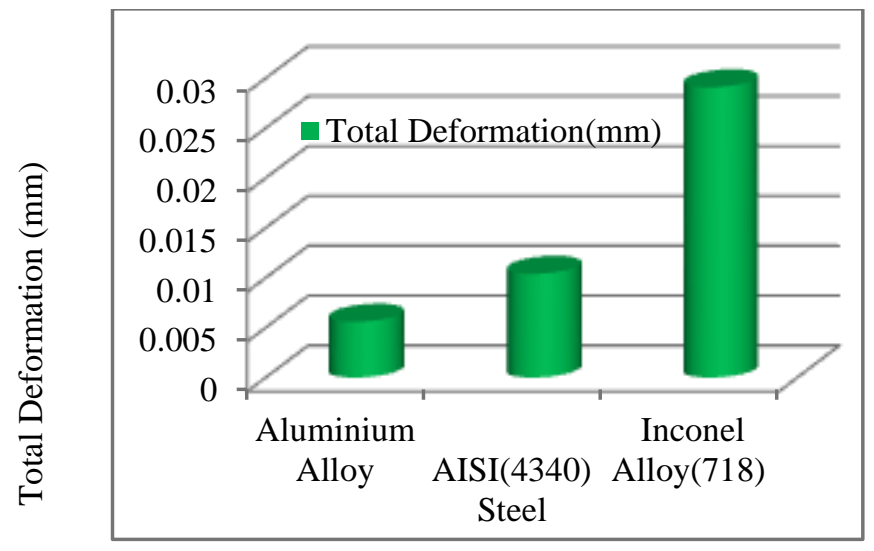

Figure 18. Comparison Results for Total Deformation

\section{CONCLUSION}

The design of the compressor impeller was carried out. The model of the turbocharger compressor was drawn using SolidWorks 2016 and was analyzed by using ANSYS 17.0. The analysis is carried out with three different materials and the results are compared. From the above results summary table, we concluded that the minimum von-Mises stress and effective strain of Aluminum Alloy (7050-T7651) are found better results than other two materials, AISI(4340) steel and Inconel Alloy (718).

The other components such as casing and diffuser are should be designed and analyzed for the future study. The casing should be analyzed to increase the efficiency by decreasing the clearance. The compressor blade design should be modified because it influences in its performance.

\section{ACKNOWLEDGMENT}

The author would like to acknowledge the support and the encouragement of Dr. EI Ei Htwe, Pro-Rector, Mandalay Technological University. The author wishes to express gratitude to Dr. Win Pa Pa Myo, Professor and Head, Department of Mechanical Engineering, Mandalay Technological University, for her guidance and suggestion for this research. The author great fully acknowledge Dr. Htay Htay Win, Professor and Supervisor, Department of Mechanical Engineering, Mandalay Technological University, for her kind permission and guidance to submit the paper to IJASRE, 2019. The author would like to thank Dr. Myint Thein, Professor, and Co-Supervisor, Department of Mechanical Engineering, Mandalay Technological University, for his great suggestions and encouragement to do this research work.

\section{REFERENCES}

1. D.Ramesh Kumar, Design and Analysis of Turbocharger Impeller in Diesel Engine, (2017).

2. CH.Satyasai Manikanta, Design and Analysis of Turbocharger Impeller, International Journal and Magazin of Engineering, Technology, Management and Research (2016).

3. Gurdeep Singh Atwal, Computational Study on Effect of Parameters on Stress of Centrifugal Compressor Blades, 2015.

4. Meha Setiya, Structural Analysis of Load Compressor Blade of Aircraft Auxiliary Power Unit, (2015).

5. Shaik Mohammad Rafi, Structure Analysis of a Turbocharger Compressor Wheel Using FEA, 2014.

6. Ajin Elias Alex, 3D Modeling and Analysis of Micro Gas Turbine Compressor Blade, 2014.

7. Khin New Zin Tun, Design and Flow Analysis of Centrifugal Compressor Impeller, 2014.

8. Rathod, A. S., Ansarim, K.: Modal and Harmonic Analysis of Turbocharger Turbine using Finite Element Method, (2013).

9. V.R.S.M. Kishore Ajjarapu, Design and Analysis of the Impeller of a Turbocharger for a Diesel Engine, (2012).

10. Anonymous, Fluid Mechanics of Turbo machinery Training Course, Kyushu Institute of Technology, Japan, (1996).

11. Ronald P. L. P. E.: Estimating Centrifugal Compressor Performance Process Compressor Technology, McGraw Hill Publications Co., (1982).

12. Shepherd, D.G: Principles of Turbo machinery, Canada, Machillan Co.Ltd., (1951).

13. J.E Shigley and C.R Mischke, Mechanical Engineering Design, McGraw Hill Publication, 5th Edition. 1989.

14. Khurmi, R.S. and Gupta J.K., Text book on Machine Design, Eurasia Publishing House, New Delhi. 